\title{
Prevalence and Description of Thrombocytopenia in Children at University Hospital Mohammed VI Marrakech
}

\author{
Lazrak Fatima Zahrae, ${ }^{1, ~}$, Skali Hajar ${ }^{2}$, Rahali Fatima Zahra ${ }^{1}$, Yahyaoui Hicham ${ }^{2}$, Sayagh Sanaa ${ }^{1}$, \\ Ait Ameur Mustapha ${ }^{2}$, Chakour Mohamed ${ }^{2}$ \\ ${ }^{1}$ Laboratory of Hematology of University Hospital Mohammed VI of Marrakech, Faculty of Medecine and Pharmacy of Marrakech, University \\ of Cadi Ayyad, Marrakech, Morocco \\ ${ }^{2}$ Hematology Laboratory Military Hospital Avicenna of Marrakech, Faculty of Medecine and Pharmacy of Marrakech, University of Cadi \\ Ayyad, Marrakech, Morocco
}

\author{
Email address: \\ fati.z.lazrak@gmail.com (L. F. Zahrae) \\ ${ }^{*}$ Corresponding author
}

\section{To cite this article:}

Lazrak Fatima Zahrae, Skali Hajar, Rahali Fatima Zahra, Yahyaoui Hicham, Sayagh Sanaa, Ait Ameur Mustapha, Chakour Mohamed. Prevalence and Description of Thrombocytopenia in Children at University Hospital Mohammed VI Marrakech. American Journal of Laboratory Medicine. Vol. 6, No. 5, 2021, pp. 77-82. doi: 10.11648/j.ajlm.20210605.12

Received: September 23, 2021; Accepted: October 11, 2021; Published: October 21, 2021

\begin{abstract}
Thrombocytopenia is defined by a number of circulating platelets less than $150 \mathrm{G} / 1$. Realization of a blood smear is necessary to find out its reality and to study platelet morphology. Several mechanisms may be involved: peripheral thrombocytopenia by destruction, consumption or hypersplenism and central thrombocytopenia dominated by haematological malignancies. The aim of this study is to describe thrombocytopenia in children received at our hospital. This is a prospective study, including all thrombocytopenic children from 0 to 15 years old who received a blood count at the Hematology Laboratory for 1 month. A blood smear will be systematically performed for false thrombocytopenia and for the study of platelet morphology. The etiological determination will be made by the exploitation of the files at the level of clinical services. The average age of patients was 4 years with extremes ranging from 2 daysAt 15 years old, predominantly female, $53 \%$ ( 24 girls/21 boys), with a sex ratio of 0.87 . Of the 45 cases, $42 \%$ were from a completed follow-up pregnancy, $15 \%$ had the concept of consanguinity in their antecedents. The myelogram showed AML in 7\% of cases, ALL in 4\%, $9 \%$ in leishmania, LMMC in 2\% and myelofibrosis in $2 \%$. Infection, leukemia and leishmaniasis with $39 \%, 25 \%$ and $11 \%$ are the most implicated causes in the development of thrombocytopenia in children in the study population. Thrombocytopenia is defined in children by a platelet count of less than $150 \mathrm{G} / \mathrm{L}$, normal values before the age of 15 years are $95 \%$ of children between 165 and $473 \mathrm{G} / \mathrm{L}$ with a median value of $299 \mathrm{G} / \mathrm{L}$ [1]. The discovery of a fortuitous thrombocytopenia during a hemogram or when the child presents to the emergencies with cutaneo-mucous haemorrhagic manifestations must initiate a rigorous diagnosis.
\end{abstract}

Keywords: Thrombopenia, Children, Hematology, Blood Smear, Platelet

\section{Introduction}

In the event of a vascular rupture, the platelets adhering to the subendothelium initiate primary hemostasis. The quantitative reduction of platelets is revealed by a hemorrhagic syndrome. Thrombocytopenia is defined by in children with a platelet count of less than $150 \mathrm{G} / \mathrm{L}$, normal values before the age of 15 are $95 \%$ of children between 165 and $473 \mathrm{G} / \mathrm{L}$ with a median value of $299 \mathrm{G} / \mathrm{L}[1,4]$. The discovery of a fortuitous thrombocytopenia during a hemogram or when the child presents in the emergency room with cutaneous and mucous hemorrhagic manifestations must initiate a rigorous diagnostic procedure. The microscopic control of the colored blood smear must verify the reality of the thrombocytopenia and eliminate the existence of a platelet mass by activation during the sampling or an underestimation of the figure by the automatic counters when the platelets are of high volume; pseudothrombopenia by in vitro agglutination is linked to the existence of antibodies dependent on the anticoagulant EDTA (ethylene diamine tetraacetic acid) from which the 
blood is drawn, directed against cryptic platelet antigens in the presence of the anticoagulant, and this false thrombocytopenia disappears when the count is performed on sodium citrate $[2,4]$. This pseudothrombopenia is not associated with any clinical problem. The very wide variety of etiologies of thrombocytopenia, depending on the mechanism involved, of central origin due to a lack of production dominated by malignant or peripheral hemopathies by consumption, anomaly of the distribution or by an immunological mechanism, undoubtedly the easiest common thread for the practitioner: specific treatment is adapted to each cause, stressing that the risk of bleeding is undoubtedly low if the platelet count is greater than $20 \mathrm{G} / \mathrm{L}$. The aim of this work is to describe thrombocytopenia in children in the pediatric departments of the Mohammed VI university Hospital in Marrakech and to determine the different etiologies. We aimed at demonstrating the diagnosis algorithm with simple clinical and biological data among a moving spectrum of diseases. However, nowadays half constitutional thrombocytopenias remain genetically undiagnosed. This proportion should be decreased in the next years, which will lead to a better management of the patients [18].

\section{Results}

\subsection{Epidemiological Data}

The average age was 4 years with extremes ranging from 4 days to 15 years. 24 cases (53\% of all cases) were female versus 21 (47\%) male.

The sex ratio was 0.87 .

In our series, $36 \%$ of the patients were in the neonatology department followed by the pediatrics department (22\%), pediatric emergencies $(20 \%)$, oncology hematology $(15 \%)$ and pediatric surgery $(7 \%)$.

\subsection{Clinical Data}

\subsubsection{History}

The antecedents are classified according to the notion of consanguinity, pregnancy history and personal history. Only $15 \%$ of the patients came from consanguineous marriage. As for the history of pregnancy, $42 \%$ of pregnant women benefited from a follow-up carried out with predominance of hospital deliveries. Furthermore, 43 patients (95\%) had no pathological history.

Table 1. Distribution according to history.

\begin{tabular}{|c|c|c|c|c|c|}
\hline \multicolumn{4}{|l|}{ History } & number & Percentage \\
\hline \multicolumn{4}{|c|}{ Inbreeding concept } & 7 & $15 \%$ \\
\hline \multirow{5}{*}{$\begin{array}{l}\text { History of } \\
\text { pregnancy }\end{array}$} & \multicolumn{3}{|c|}{ Concept of follow-up } & 19 & $42 \%$ \\
\hline & \multirow{4}{*}{ Childbirth } & \multirow{2}{*}{ Places } & Hospital & 35 & $77.7 \%$ \\
\hline & & & Home & 10 & $22.2 \%$ \\
\hline & & \multirow{2}{*}{ track } & Lower & 36 & $80 \%$ \\
\hline & & & caesarean & 2 & $20 \%$ \\
\hline \multirow{3}{*}{$\begin{array}{l}\text { Personal } \\
\text { history }\end{array}$} & \multicolumn{3}{|l|}{ medical } & 43 & $95 \%$ \\
\hline & \multicolumn{3}{|c|}{ surgical } & 43 & $95 \%$ \\
\hline & \multicolumn{3}{|c|}{ Recent vaccination } & 40 & $88.8 \%$ \\
\hline
\end{tabular}

\subsubsection{Circumstances of Discovery}

26 patients (57\%) thrombocytopenia appears immediately. Whereas in 19 patients $(42 \%)$ it appears after 48 hours of hospitalization with extremes ranging from 3 to 10 days.

In our series, 19 patients (42\%) had a hemorrhagic syndrome including $26 \%$ in hematological oncology and neonatology, $21 \%$ in pediatric emergencies, $15 \%$ in surgery and $10 \%$ in pediatrics.

The clinical examination found disturbances of consciousness in $4 \%$ of the cases, a tumor syndrome in $29 \%$, fever in $42 \%$. (table 2 )

Table 2. Distribution according to data from the clinical examination

\begin{tabular}{lll}
\hline Physical examination & Number & Percentage \\
\hline Consciousness (drowsiness) & 2 & $4 \%$ \\
Tumor syndrome & 13 & $29 \%$ \\
Fever & 19 & $42 \%$ \\
Normal psychomotor development & 45 & $100 \%$ \\
\hline
\end{tabular}

\section{Biological Data}

\subsection{Blood Count}

Isolated thrombocytopenia was in 23 patients or $57 \%, 10$ patients had anemia associated with thrombocytopenia $25 \%$ of which 2 patients had HUS then 6 had pancytopenia or $15 \%$ and finally 6 patients presented with a leukocytosis associated with thrombocytopenia.

\subsection{Blood Smear}

The blood smear was an important diagnostic tool, it made it possible to object leukemia in $14 \%$ of the cases and to eliminate a false thrombocytopenia by presence of platelet aggregates in $25 \%$ of the cases.

The study of erythrocyte morphology noted the presence of schizocytes in $4 \%$, poikilocytosis in $9 \%$ and Joly's bodies in $11 \%$.

The grainy line study noted myelemia in $9 \%$ of cases and the presence of vacuolated PNN in $31 \%$. (Table 3 )

Table 3. Distribution according to the blood smear data.

\begin{tabular}{llll}
\hline Blood smear & & Number & Percentage \\
\hline \multirow{2}{*}{ Thrombocytopenia } & True & 34 & $75 \%$ \\
& $\begin{array}{l}\text { False (Presence of } \\
\text { platelet aggregates) }\end{array}$ & 11 & $25 \%$ \\
& Schizocyte & 2 & $4 \%$ \\
GR abnormalities & poikilocytosis & 4 & $9 \%$ \\
& Jolly body & 5 & $11 \%$ \\
granular line & Vacuolated PNN & 14 & $31 \%$ \\
abnormalities & myelemia & 4 & $9 \%$ \\
blasts & & 6 & $14 \%$ \\
\hline
\end{tabular}

\subsection{Myelogram}

In our series, the myelogram objectified AML in $7 \%$ of cases, ALL in 4\%, $9 \%$ had leishmanian bodies, LMMC in $2 \%$ and myelofibrosis in $2 \%$. 


\section{Discussion}

\subsection{Epidemiology}

\subsubsection{Distribution by Age}

The average age of our patients was 4 years, but age does not represent a risk factor for the development of thrombocytopenia [1].

\subsubsection{Distribution by Gender}

In our study, we note a slight predominance of the female sex, with $52 \%$ of cases. Sex does not present a risk factor for the development of thrombocytopenia [1].

\subsubsection{Distribution According to Services}

TNN are frequent, representing $20 \%$ of hospitalized in neonatology and intensive care units [3], which is consistent with our series where $36 \%$ of our patients were in the neonatology department.

\subsection{Diagnostic Approach}

Thrombocytopenia in children, present at admission or developed during the stay is a frequent event, the poor prognostic value of which has been underlined by numerous studies. The definition of thrombocytopenia is defined according to studies by a platelet count $<150 \mathrm{G} / \mathrm{L}$ or $<100 \mathrm{G} / \mathrm{L}$. The significant decrease (generally $50 \%$ ) in the platelet count compared to a reference value has the same meaning, and the common pathophysiological mechanisms justify a similar diagnostic approach. [4]

The diagnostic approach to thrombocytopenia includes the following steps:

1. Confirm the reality of thrombocytopenia.

2. Appreciate the clinical context and the risk of bleeding.

3. Identify the central or peripheral mechanism.

\subsubsection{Confirmation of the Reality of Thrombocytopenia}

The diagnosis of thrombocytopenia is easy thanks to the frequent prescription of blood counts. But this thrombocytopenia must always be confirmed by ruling out a false thrombocytopenia by in vitro agglutination of the platelets by carrying out a blood smear.

Pseudo-thrombocytopenia is divided into two main groups: dependent EDTA pseudo-thrombopenia and independent EDTA pseudo-thrombopenia (Table 1). Hematology machines are particle counters that only count free particles (white blood cells, red blood cells and platelets). For various reasons if the figured elements of the blood are arranged in aggregates, the circulating free particles decrease and the device will systematically give a false determination of the real level of these particles. [5]

Table 4. Causes of false account of thrombopenia.

\begin{tabular}{ll}
\hline Pseudothrombocytoses: & Pseudothrombopenia \\
\hline 1) Schizocytes & EDTA dependent: \\
2) Microcytes (VGM $<60 \mathrm{fL})$ & 1) aggregates \\
3) Cytoplasmic debris & 2) orbiting \\
4) Bacteria & Independent EDTA: \\
5) Parasites (Plasmodium sp.) & 1) autoimmune in nature \\
6) Yeasts & 2) physical in nature \\
7) Cryoproteins & 3) chemical in nature \\
\hline
\end{tabular}

The average frequency of pseudo thrombocytopenia is estimated at $0.1 \%$ [5]. In our series, false thrombocytopenia was estimated at $25 \%$, hence the need to avoid preanalytical errors (such as difficult sampling, a defect in anticoagulant by overfilling the tube and a lack of agitation).

In the absence of aggregates, the reality of thrombocytopenia is confirmed, the causes potentially visible on the smear will then be sought in order to guide the diagnosis: schizocytes during HUS, blasts during acute leukemias but also PNN vacuolated during infections [6] hence the need to carry out a careful examination, which is the case in our studies where we objectified $4 \%$ of schizocytes, $31 \%$ of vacuolated PNN and $14 \%$ of blasts.

Table 5. Drugs involved in the occurrence of thrombocytopenia.

\begin{tabular}{ll}
\hline Therapeutic family & Drugs involved \\
\hline Heparin & unfractionated heparin, high molecular weight heparin \\
Antiplatelet agents (anti-GpIIB/lia) & Abciximab, aspirin, eptifibatid, tirofiban, ticlopidin \\
quinidine & Quinin, quinidin \\
antibiotics & Amphotericin B, ethambutol \\
antiFungal & Fluconazole, linezolid, nalidixiqu acid, rifampicin, trimethoprim-sulfamethoxazol, vancomycin \\
Antihyperteurs & Alpha-methyl-dopa, alprenolol \\
antiarrhythmics & Amiodarone, captopril, digoxin \\
diuretics & minoxidil, oxprenolol \\
analgesics & Diclofenac, D. penicillamin, ibuprofen \\
Nonsteroidal anti-inflammatory drugs & Naproxen, paracetamol, gold salt \\
antirheumatic & Sulfasalazine \\
Chemotherapies and immunosuppressants & All Chemotherapies and specially fludarabin, ciclosporin, alpha interferon, oxaliplatin, anti-bodies anti-CD20, \\
psychotropic & tamoxifen \\
antiepileptic & Diazepam, carbamazepin, haloperidol, \\
antihistamines & Lithium Valpoic acid \\
antiulcer & \\
\hline
\end{tabular}

\subsubsection{Assess the Clinical Context and the Risk of Bleeding}

The data from the interrogation make it possible to appreciate the importance of the hemorrhagic syndrome and to look for signs of gravity (cutaneous-mucous bleeding, headache causing fear of a cerebromeningeal hemorrhage, digestive hemorrhage, 
etc.), to assess the age of the thrombocytopenia which will indeed guide the diagnosis; may evoke constitutional thrombocytopenia; and thus partially condition the therapeutic indications. The ingestion of certain drugs can conventionally be complicated by thrombocytopenia (Table 2) [7].

\begin{tabular}{|c|c|}
\hline Famille thérapeutique & Médicaments impliquếs (DCD) \\
\hline Héparines & Héparine non fractionnée, HBPM \\
\hline $\begin{array}{l}\text { Antiagrégants plaquettaires } \\
\text { Anti-GpIIb/Mla }\end{array}$ & $\begin{array}{l}\text { Abciximab, aspirine, eptifibatide, } \\
\text { tirofiban, ticlopidine }\end{array}$ \\
\hline Quinidiniques & Quinine, quinidine \\
\hline $\begin{array}{l}\text { Antibiotiques } \\
\text { Antifongiques }\end{array}$ & $\begin{array}{l}\text { Amphotéricine B, éthambutol, } \\
\text { fluconazole, linézolide, acide } \\
\text { nalidixique, rifampicine, } \\
\text { triméthoprime-sulfaméthoxazole, } \\
\text { vancomycine }\end{array}$ \\
\hline $\begin{array}{l}\text { Antihypertenseurs } \\
\text { Antiarythmiques } \\
\text { Diurćtiques }\end{array}$ & $\begin{array}{l}\text { Npha-méthyl-dopa, alprénolol, } \\
\text { amiodarone, captopril, digoxine, } \\
\text { minoxidil, oxprénolol }\end{array}$ \\
\hline $\begin{array}{l}\text { Antalgiques } \\
\text { AINS } \\
\text { Médicaments } \\
\text { antirhumatismaux }\end{array}$ & $\begin{array}{l}\text { Diclofénac, D-pénicillamine, ibuproféne, } \\
\text { naproxène, paracétamol, sels d'or, } \\
\text { sulfasalazine }\end{array}$ \\
\hline $\begin{array}{l}\text { Chimiothérapies et } \\
\text { immunosuppresseurs }\end{array}$ & $\begin{array}{l}\text { Toutes les chimiothérapies, et en } \\
\text { particulier fludarabine, ciclosporine, } \\
\text { interféron alpha, oxaliplatine, anticorps } \\
\text { anti-CD20, tamoxifene }\end{array}$ \\
\hline $\begin{array}{l}\text { Psychotropes } \\
\text { Anticomitiaux }\end{array}$ & $\begin{array}{l}\text { Diaxépam, carbamaxx́pine, halopéridol, } \\
\text { lithium } \\
\text { Acide valprö̈que }\end{array}$ \\
\hline \multicolumn{2}{|l|}{ Antihistaminiques } \\
\hline Antiulcéreux & Cimćtidine, ranitidine, oméprazole \\
\hline
\end{tabular}

Figure 1. Drugs involved in the occurence of thrombocytopenia

The existence of organomegaly on clinical examination (hepato-splenomegaly, lymphadenopathy) points to central thrombocytopenia, a satellite of malignant hemopathy, or to thrombocytopenia associated with HIV infection or certain immune deficits (immune deficits common variable, autoimmune lymphoproliferative syndrome) [7]. In the presence of splenomegaly, suggests hypersplenism. Finally, any serious infectious syndrome can be accompanied by sometimes severe thrombocytopenia, essentially linked to a mechanism of consumption [7].

\subsubsection{Etiologies}

Thrombocytopenia is the most frequent hemostatic disorder in intensive care where the mechanisms and etiologies are often multiple, with a large predominance of peripheral causes [8]. Sepsis remains the main cause of thrombocytopenia in intensive care, most often associated with disseminated intravascular coagulation (DIC) [9].

\section{(i). Peripheral Thrombocytopenia}

a. Sepsis:

Sepsis is an important risk factor for thrombocytopenia in intensive care. There is a correlation between the importance of thrombocytopenia and the severity of sepsis [9]. Thrombocytopenia in intensive care - 9- The main mechanisms are the decline in production, destruction or sequestration of platelets in the spleen. But during sepsis, the peripheral mechanisms are very preponderant, making the appreciation of the medullary richness in megakaryocytes useless in daily practice in the patient's bed. The three main mechanisms are disseminated intravascular coagulation (DIC), immunological mechanisms and macrophagic activation syndrome (SAM).

b. leishmaniasis

Leishmaniases are diseases caused by parasites of the genus Leishmania or leishmanias which include many species. Common to humans and some animals, they are transmitted by the bite of the female of a small gnat called sandfly or "sand fly" found in forests, rural areas and around cities. These vector-borne diseases therefore experience the same seasonal variation as those of sandfly populations and occur in different clinical forms depending on the parasitic species involved.

Visceral leishmaniasis is favored by deficits in cellular immunity, whether of viral origin (HIV infection) or iatrogenic (immunosuppressants, corticosteroids, chemotherapy...), as is the case here. The cardinal signs are fever, splenomegaly, skin-mucous pallor, frequent deterioration of the general state and sometimes hepatomegaly. Pancytopenia is a classic sign and visceral leishmaniasis is sometimes even revealed by a macrophagic activation syndrome. It can be accompanied by manifestations of an autoimmune appearance (arthralgia, purpura, positive autoantibodies) which may be necessary for an outbreak of disease. Liposomal amphotericin B is the gold standard. It must be prolonged in the immunocompromised because relapses are frequent. [10].

c. Hemolytic uremic syndrome:

Hemolytic uremic syndrome (HUS) is defined by the simultaneous occurrence of microangiopathic hemolytic anemia, thrombocytopenia, and renal disease. It is the main cause of acute kidney failure in children under the age of three. In its typical form, HUS occurs during the summer period after an episode of diarrhea, often bloody. The typical HUS is secondary to an enteropathogenic Escherichia coli infection, in particular the serotype O157: H7, producer of venotoxin (VT). Other infections can cause HUS.

Besides the typical form, some patients have a different presentation. The atypical forms of HUS occur without prodromes and have a more chronic course, frequently leading to chronic renal failure. Atypical HUS can occur at any age and can develop by pushing. [11]

d. Post-transfusion purpura:

Post-transfusion purpura (PPT) is a rare but severe cause of life-threatening thrombocytopenia due to patients' deep thrombocytopenia. The pathophysiology of this syndrome is complex. PPT is linked to alloimmunization during the transfusion of red blood cells. Thus it occurs within two to fourteen days post-transfusion, and is linked to sensitization to HPA antigens (an alloimmunization linked to the presence of Anti-HPA-1a). Alloimmunization against platelet antigens can occur during pregnancy, after transfusion or after transplantation. It is the consequence of the presence in the 
circulation of the recipient of platelets carrying foreign antigens. The antibodies are directed against these antigens present on these foreign platelets and absent on the recipient's platelets. Allo-antibodies against human platelet antigens are responsible for the clinical forms of alloimmune neonatal thrombocytopenia, post-transfusion purpura, alloimmune passive thrombocytopenia, alloimmune thrombocytopenia associated with transplants and for therapeutic efficacy. of a state refractory to transfusions. The occurrence of severe thrombocytopenia 5 to 10 days after a transfusion is suggestive. Any transfusion containing platelets or platelet antigens can induce PPT: platelet concentrates obviously, but also CGR or plasma, which may contain residual platelets. [12]

\section{(ii). Central Thrombocytopenia}

They are objectified by a myelogram finding little or no megakaryocytes and are often associated with damage to other lines and they are frequent in pediatrics. The main causes are: -Malignant hemopathies (lymphoid hemopathies, acute leukemias)

1. Idiopathic bone marrow aplasia or secondary to exposure to a toxic agent (radiotherapy, chemotherapy, drugs) or to a viral infection.

2. Invasions by metastatic cells.

3. Constitutional central thrombocytopenia is rarer.

Acute leukemia (AL) is a heterogeneous group of malignant hemopathies characterized by the uncontrolled clonal proliferation of hematopoietic precursors blocked in their differentiation. They represent between 10 and $15 \%$ of malignant hemopathies with an incidence rate standardized to the world population of less than 6/100,000 inhabitants/year [13] and an age of onset which varies according to the type of leukemia [14]. In children, acute myeloid leukemia (AML) is rare and occurs before the age of 2 years or after 15 years. Conversely, Acute lymphoblastic leukemia (ALL) is the most common cancer in children and accounts for about a quarter of all cancers in people under the age of 15 [15] and is also about 5 times more prevalent than the LAM [16]. Leukemia is the most common pediatric cancer and there are two main types of LA; LAL and LAM. The abnormalities in the hemogram in our study were mainly represented by thrombocytopenia followed by anemia and then hyperleukocytosis. These results are similar to those in the literature [17]. The intensity of thrombocytopenia and the risk of bleeding are frequent signs in leukemia [17].

\section{Conclusion}

Thrombocytopenia is a very common situation in children. With thrombocytopenia, it is necessary to eliminate a false thrombocytopenia by agglutination in platelets by performing an examination of the blood film and, if necessary, on citrate.

Thrombocytopenia is often indicative of an unknown situation.

\section{References}

[1] Ginevra Biino, Iolanda Santimone, Cosetta Minelli, Rossella Sorice et al. Age- And Sex-Related Variations in Platelet Count in Italy: A Proposal of Reference Ranges Based on 40987 Subjects' Data. Plos One 2013.

[2] Bizzaro N. EDTA-dependant pseudothrombocytopenia: a clinical and epidemiological study of 112 cases, with 10-years follow up. Am J Hematol 1995; 50: 103-9.

[3] Saxonhouse MD, Martha C. Sola Visner. Thrombocytopenia in the neonatal intensive care unit. Neoreviews 2009, 10: 435-45.

[4] J. -L. Stephan, C. Sevrez, S. Thouvenin-Doulet. Les thrombopénies de l'enfant. Elsevier Massion 2015.

[5] Nakul-Aquaronne, D., El Yakine, A., Starck, B., \& Bayle, J. (2002). Les pièges de la numération auto matique des plaquettes. Revue Française Des Laboratoires, 2002 (347), 2125 .

[6] Barbara J. Bain, F. R. A. C. P., F. R. C. Path. Diagnosis from the Blood Smear. N Engl J Med 2005; 353: 498-507.

[7] B. Godeau, P. Bierling. Thrombopénies. Elsevier Masson 2012.

[8] Jaudrot. M, Nurden. P. Des fonctions plaquettaires aux implications thérapeutiques. La revue de médecine interne (2010), vol 31, nS3: 319-323.

[9] Levi. M, Schultz. M. Coagulopathie and platelet disorders in critically ill patients. Minerva Anestesiologia; 2010; vol 76: 851-859.

[10] C. Tabouret, A. Monier, O. Souchaud-Debouverie, F. Roy-Peaud, P. Roblot. 72e Congrès de la Société nationale franc, aise de médecine interne, Tours, 10-12 décembre 2015/La Revue de médecine interne 36S (2015) A100-A211.

[11] Patrick Niaudet. Syndrome Hemolytique et urémique chez l'enfant. Elsevier Masson 2007.

[12] Brenet, O., Le Rolle, T., Chapillon, M., Soroko, M., Poirier, N., \& Bidet, M. (1998). Purpura posttransfusionnel: une cause de thrombopénie postopératoire grave. Annales Françaises d'Anesthésie et de Réanimation.

[13] Gemma Gatta, Jan Maarten van der Zwan, Paolo G. Casali, Sabine Siesling, Angelo Paolo Dei Tos, IanKunkler, RenéeOtter, LisaLicitra, SandraMallone, AndreaTa villa, Annalisa Trama, RiccardoCapocaccia, The RARECARE working group. Rare cancers are not so rare: the rare cancer burden in Europe. Eur J Cancer 2011; 47 (17): 2493511. PubMed $\mid$ Google Scholar.

[14] Vardiman JW, Thiele J, Arber DA, Brunning RD, Borowitz MJ, Porwit A, Harris NL, Le Beau MM, Hellström-Lindberg E, Tefferi A, Bloomfield CD. The 2008 revision of the World Health Organization (WHO) classification of myeloid neoplasms and acute leukemia: rationale and important changes. Blood. 2009; 114 (5): 937-5. PubMed | Google Scholar.

[15] Janet M Torpy, CassioLynm, MA, Richard M. Acute Lymphoblastic Leukemia. JAMA. 2009; 301 (4): 452. PubMed | Google Scholar.

[16] Michèle Imbert, Orianne Wagner-Ballon. Place de la biologie moléculaire pour le diagnostic et le suivi des leucémies aiguës. Rev Fr Lab. 2015; 471: 29-33. PubMed | Google Scholar. 
[17] Sophie Bustany, Michelle Malet, VeroniqueSalaun, Dina Naguib, Ghislaine Plessis, Xavier Troussard. La leucémie peu différenciée (MO): aspect hématologique, immunophénotypique, cytogénétique, incidence pronostique expérience de Caen. RevFrLab. 2007; 37 (395): 5158. PubMed | Google Scholar.
[18] H. Boutrouxa M. - D. Tabonea H. Lapillonnebd P. Ballerinibd R. avierbce G. Levergeracd, Constitutional thrombocytopenias: From clinical features to the news inputs of genetics, Revue d'Oncologie Hématologie Pédiatrique Volume 1, Issue 2, October 2013, Pages 89-97. 